\title{
ADRENALECTOMY FOR ISOLATED META- STASES
}

\author{
Svetlana Shumarova ${ }^{1}$, Damyan Petrov ${ }^{2}$, Konstantin Grozdev ${ }^{1}$, Anatoli Semkov ${ }^{3}$, \\ Danail Petrov ${ }^{3}$, George Todorov ${ }^{1}$. \\ 1) Department of Surgery, University Hospital Aleksandrovska Sofia, Bulgaria, \\ Medical University, Sofia, Bulgaria; \\ 2) Department of Social Medicine and Health Management, Medical Faculty, \\ Trakia University, Stara Zagora, Bulgaria; \\ 3) Department of Thoracic Surgery, Saint Sophia Hospital for Pulmonary Dis- \\ eases, Sofia, Bulgaria.
}

\begin{abstract}
Background: Isolated adrenal gland metastases are not frequently finding. The aim of the present retrospective study was to estimate clinical and pathological parameters that could be used to predict survival after adrenalectomy.

Material and methods: A total of 34 patients with adrenal gland masses suspected to be metastases was included in this study. The group of patients with isolated metastases was $19(56 \%)$ and a group of patients with adrenal adenomas $-15(44 \%)$.

Results: The sample of patients consisted of 18 (53\%) men and $16(47 \%)$ women from 40 to 81 years old with a mean $( \pm$ SD) age of $61.6 \pm 10.3$ years, presented with adrenal mass suspected to be metastases. Nineteen $(56 \%)$ of them had demonstrated metastases and $16(84 \%)$ metachronous with median overall survival (OS) 54.6 (range 43-66) months. Median OS in the group with metastases was 22.6 months. Lung carcinoma was the most common primary tumour metastasizing in the adrenal gland $-58 \%$ of all metastases with a disease-free interval (DFI) of 13 months. It was presented by shorter median survival than the rest primary tumour types (37.8 vs. 96.7 months; logrank test, $\mathrm{p}=0.028$ ). In the multivariate Cox's hazard analysis of the surgical technique was found to be an independent prognostic factor $(\mathrm{p}=0.047)$, together with lung carcinoma vs. renal cell carcinoma $(\mathrm{p}=0.045)$.

Conclusion: Adrenalectomy due to isolated metastases in the adrenal glands showed the median overall survival of 22.6 months. Shorter survival periods were associated with lung carcinoma, DFI $<12$ months, conversion to open surgery, synchronous metastases, but not with age, tumour size or resection status.
\end{abstract}

Keywords: adrenal gland, adrenal metastases, adrenalectomy, laparoscopic adrenalectomy.

\section{INTRODUCTION}

A series of primary malignant diseases can metastasize into the adrenal glands [1, 2]. According to some authors, the abundant sinusoidal blood flow and the nu- merous arterial perfusion pathways contribute to the high incidence of metastatic implantation [2]. Metastasis in the adrenal gland have been reported in autopsy in $27-38 \%$ of patients with known extra-adrenal malignancy [1, 3, 4], but isolated metastases have been established in less than $1 \%$ of those cases [4]. Lung, kidney, and bowel carcinoma, melanoma and breast cancer most often metastasize into the adrenal glands [5-8].

An adrenal metastasis is usually limited to the adrenal gland, which provides better chances for its total removal $[6,9,10]$. Long-term survival rates have been reported in patients after adrenalectomy due to metastatic disease, provided there was an isolated metastasis [3, 1113]. In terms of surgical approach, numerous authors have reported safety and similar oncological results of laparoscopic adrenalectomy for metastases compared to open surgery $[11,12,14-16]$. In the present study, we have presented our clinical results from the endoscopic removal of suspected adrenal metastases, and have tried to evaluate the significance of certain clinical and pathological parameters for prediction of long-term survival after adrenalectomy.

\section{MATERIAL AND METHODS}

We performed a retrospective study involving 34 patients, operated by various malignancies with a tumour in the adrenal gland, for the period from January 2005 to May 2015 in the Clinic of Surgery of the University Hospital "Aleksandrovska". Data was collected using medical documents. The selection of the adrenal tumours was carried out by means of computed tomography (CT) to 26 (76\%) of the patients, where the density of tumour was compared to the density of water, adopted as $0 \mathrm{HU}$ (Hounsfield units). Adrenal metastases with HU > 18 were detected in 11(43\%) of these 26 patients, and adrenal adenomas with limit values between 10 and $16 \mathrm{HU}$ were noted in 15 (57\%), which cannot exclude malignancy. Three $(9 \%)$ patients with demonstrated adrenal metastases $\mathrm{T} 2$-series of the magnetic resonance imaging (MRI) showed heterogeneity and hyper intensity without any loss of signal intensity. Metastases were established in the rest $5(15 \%)$ patients by using positron- 
emission tomography (PET) with a ratio of the standardised uptake values (SUV) adrenal gland/liver $>1$, which is a common criterion for differentiation between malignant and benignant lesions. Overall survival (OS) was defined as the time interval from the date of adrenalectomy to the date of follow-up (01. 11. 2015) or death. Disease-free interval (DFI) was defined as the interval between the primary resection and the recognition of an adrenal mass. All of 34 patients underwent adrenalectomy. Nineteen (56\%) had synchronous ( $\leq 6$ months post resection) or metachronous ( $>6$ months post resection) metastases, demonstrated histologically. These are solitary lesions, such as adrenal gland is the only and first site of metastasizing. With R0 we marked the cases of complete macroscopic and microscopic resection as a final histological result, and with $\mathrm{R} 1$ - complete macroscopic resection with positive resection lines.

Cumulative survival curves were drawn by the Kaplan-Meier method and the differences between the curves were analysed by Mantel-Cox (long-rank) test. The Cox's proportional hazard model was used for the multivariate analysis performed with the factors that were statistically significant in the univariate analysis. Statistical significance was accepted at $\mathrm{p}<0.05$.

All data for this study were analysed using the IBM SPSS v 24.0.

\section{RESULTS}

In total, 34 patients with adrenal metastases $18(53 \%)$ men and 16(47\%) women were studied in this group. The mean $( \pm \mathrm{SD})$ age of the patients was $61.6 \pm 10.3$ (range 40 81 ) years. (Adrenalectomy was performed to all 34 patients with adrenal tumour mass; in $24(71 \%)$ - retroperitoneal endoscopic adrenalectomy (REA) with a lateral approach, and in $10(29 \%)$ - conversion to open surgery. Reasons for converting to open adrenalectomy are the big size of the tumour or adhesions to the vena cava and the superior pole of the kidney. Median surgery time of the endoscopic procedures was 85 (range 60-120) min, with median intraoperative blood loss of $80(0-300) \mathrm{ml}$. No intra- or postoperative complications were observed. The average hospital stay after endoscopic adrenalectomy was 4 days, and after conversion - 11 days. No port-site metastases or surgical lethality was recorded. The main cause of death was a progression of the primary disease. Median tumour size was estimated as 39 (12-100) mm. Left-sided localisation was observed in 20(59\%) patients, and right-sided - in 14 (41\%). The most common primary tumour was lung carcinoma $-15(44 \%)$, followed by breast cancer $-7(21 \%)$, renal-cell carcinoma $-3(9 \%)$, and carcinoma of the rectum $-3(9 \%)$, sigmoid colon $-2(6 \%)$, urinary bladder $-1(3 \%)$, endometrium - $1(3 \%)$, cervix $-2(6 \%)$, thyroid gland -1 $(3 \%)$, malignant myeloma $-1(3 \%)$ and seminoma -1 $(3 \%)$.

Adrenal metastases from the primary tumour were established in $19(56 \%)$ of the patients - $16(84 \%)$ metachronous and $3(16 \%)$ synchronous, while in $15(44 \%)$ there was adrenal hyperplasia or adenoma. Mean overall survival of the patients with metastasis was 25 months.

In our study, we observed a statistically significant difference between the survival of patients with metastases and their gender, since all women in the study $(n=5)$ survived (log rank test; $\mathrm{p}=0.022$ ) (Table 1 ). Median survival time in women was 65.1 (23.0-90.1) months, and in men 42.6 (5.2-124.1) months. The factors age group (log rank test; $\mathrm{p}=0.845)$, tumour size (log rank test; $\mathrm{p}=0.621)$ and resection status R0/R1 (log rank test; $\mathrm{p}=0.484$ ) were non-statistically significant (Table 2). Median survival in the group of patients with status R0 was 54.7 months, and at R1 was 49.1 months.

Table 1. Demographic data for patients with isolated adrenal metastases

\begin{tabular}{|c|c|c|c|}
\hline Characteristic & Alive $(\mathrm{n}=8,56 \%)$ & Dead $(n=11,44 \%)$ & $\mathrm{p}$ \\
\hline Age(years), mean $\pm \mathrm{SD}$ & $58.4 \pm 7.9$ & $61.7 \pm 10,9$ & 0.470 \\
\hline Gender $(\mathrm{M} / \mathrm{F})$ & $3(37.5 \%) / 5(62,5 \%)$ & $11(100 \%) / 0(0 \%)$ & 0.005 \\
\hline Primary tumour & & & 0.371 \\
\hline lung carcinoma & $3(37.5 \%)$ & $8(72.7 \%)$ & \\
\hline renal cell carcinoma & $2(25.0 \%)$ & $1(9.1 \%)$ & \\
\hline other & $3(37.5 \%)$ & $2(18.2 \%)$ & \\
\hline Tumour size $(\mathrm{mm})$, mean $\pm \mathrm{SD}$ & $47.6 \pm 28.3$ & $50.5 \pm 22.3$ & 0.809 \\
\hline $\begin{array}{l}\text { Surgical technique (conversion } \\
\text { to open surgery/REA) }\end{array}$ & $2(25 \%) / 6(75 \%)$ & $6(54.5 \%) / 5(45.5 \%)$ & 0.352 \\
\hline $\begin{array}{l}\text { Presentation } \\
\text { (metachronous/synchronous) }\end{array}$ & $8(100 \%) / 0(0 \%)$ & $8(72.7 \%) / 3(27.3 \%)$ & 0.228 \\
\hline DFI ( $<12$ month/ $\geq 12$ month $)$ & $1(12.5 \%) / 7(87.5 \%)$ & $4(36.4 \%) / 7(63.6 \%)$ & 0.338 \\
\hline Resection status (R0/R1) & $6(75.0 \%) / 2(25.0 \%)$ & $8(72.7 \%) / 3(27.3 \%)$ & 1.000 \\
\hline
\end{tabular}


Table 2. Univariate and multivariate analysis of overall survival in patients with isolated adrenal metastases

\begin{tabular}{|c|c|c|c|c|c|}
\hline \multirow[t]{2}{*}{ Variable } & \multirow[t]{2}{*}{$\begin{array}{l}\text { Mean survival in } \\
\text { months }(95 \% \mathrm{CI})\end{array}$} & \multicolumn{2}{|c|}{$\begin{array}{c}\text { Univariate } \\
\text { analyses }\end{array}$} & \multicolumn{2}{|c|}{$\begin{array}{c}\text { Multivariate } \\
\text { analyses }\end{array}$} \\
\hline & & $\mathrm{p}$ & $\mathrm{HR}$ & $\mathrm{p}$ & HR \\
\hline Surgical technique & & 0.025 & & 0.047 & \\
\hline Conversion to open surgery $(n=8)$ & $29(17-40)$ & & 0.244 & & 0.079 \\
\hline $\operatorname{REA}(\mathrm{n}=11)$ & $59(46-73)$ & & 1 & & 1 \\
\hline Tumour type & & 0.089 & & 0.034 & \\
\hline Lung carcinoma $(\mathrm{n}=11)$ & $38(26-50)$ & & 1 & & 1 \\
\hline Renal cell carcinoma $(n=3)$ & $78(34-122)$ & 0.254 & 0.296 & $0.045^{\mathrm{a}}$ & 0.047 \\
\hline Other $(n=5)$ & $97(67-126)$ & 0.041 & 0.188 & $0.227^{\mathrm{a}}$ & 0.327 \\
\hline Disease-free interval & & 0.031 & & & \\
\hline Metachronous DFI $<12$ months $(\mathrm{n}=3)$ & $32(-)$ & & 0.069 & & \\
\hline Metachronous DFI $\geq 12$ months $(\mathrm{n}=14)$ & $59(47-71)$ & & 1 & & \\
\hline Size of tumour & & 0.622 & & n.s. & \\
\hline$\leq 45 \mathrm{~mm}(\mathrm{n}=9)$ & $55(48-62)$ & & 1 & & \\
\hline$>45$ mm $(\mathrm{n}=10)$ & $47(32-61)$ & & 1.349 & & \\
\hline Presentation & & 0.006 & & 0.309 & \\
\hline Synchronous $(\mathrm{n}=3)$ & $24(0-55)$ & & 0.041 & & 0.286 \\
\hline Metachronous $(n=16)$ & $55(43-66)$ & & 1 & & 1 \\
\hline Resection status & & 0.488 & & n.s. & \\
\hline $\operatorname{Ro}(n=14)$ & $55(41-69)$ & & 1.604 & & \\
\hline $\mathrm{R} 1(\mathrm{n}=5)$ & $49(0-99)$ & & 1 & & \\
\hline Age & & 0.846 & & n.s. & \\
\hline$\leq 55(n=7)$ & $52(29-75)$ & & 1.131 & & \\
\hline$>55(\mathrm{n}=12)$ & $55(32-77)$ & & 0 & & \\
\hline
\end{tabular}

a versus lung carcinoma

Statistical difference in survival between synchronous and metachronous adrenal metastasis (log rank test; $\mathrm{p}<0.0001$ ) was found. Median survival for metachronous metastases was 54.7 months, and for synchronous -24.2 months (Fig. 1A, Table 2). By the end of the follow-up all patients with synchronous metastases were dead, while $50 \%$ of those with metachronous were still alive (Table 1). We observed the difference in the DFI in patients with various types of primary tumours and adrenal gland metastases (Table 3 ). The shortest survival was associated with lung carcinoma, followed by renal cell carcinoma. The longest DFI was in colorectal carcinoma. Due to the small sample of some types of primary tumours, for the purpose of the Kaplan-Meier analysis, we have combined those with less frequency as the "other" group (Fig. 1B). Patients with lung carcinoma had shorter median survival (37.8 vs 96.7 months; log-rank test, $\mathrm{p}=0.028$ ) (Table 2) than patient with renal cell carcinoma. We observed a statistical dependence in terms $\mathrm{DFI}<12$ months and DFI $>12$ months (log rank test; $p=0.005$ ) (Fig. 1C, Table 2). The median survival of patients with DFI $<12$ months was 31.6 months, and for DFI $>12$ months - 59.1months. Of the patients with DFI < 12 months only $20 \%$ survived, while at DFI $>12$ months $50 \%$ were still alive by the end of the follow-up (Table 1 ). Also, there was a difference in survival between the patients with REA and those with open adrenalectomy (log-rank test; $\mathrm{p}=0.016$ ), as the median survival of the first was 59.2 months, and of the second - 28.9 months (Fig. 1D, Table 2). 
Fig. 1. Survival curves in a relationship with presentation (A), primary tumour (B), DFI (C) and surgical technique (D).
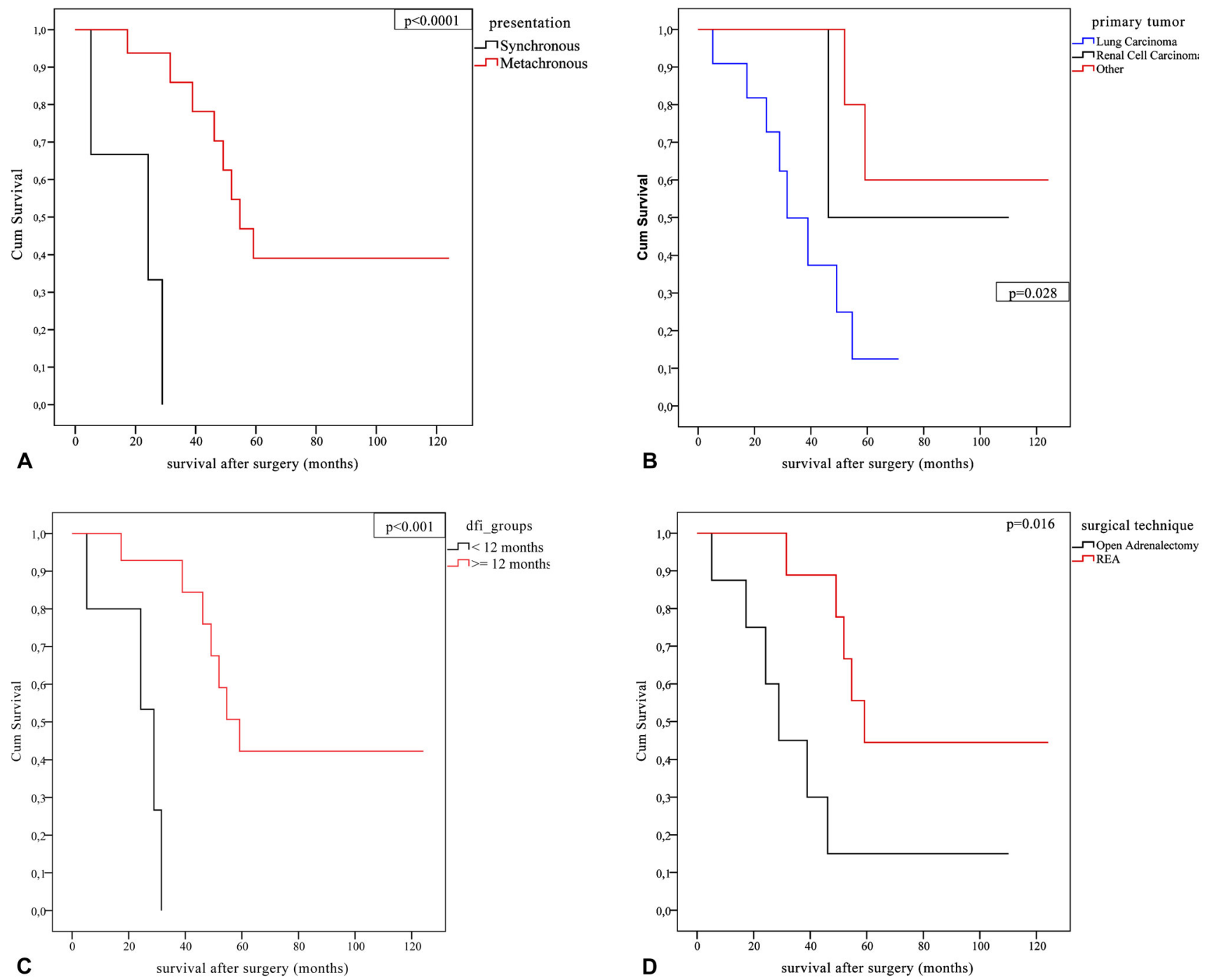

Table 3. Disease-free interval according to the primary tumour type in patients with isolated metastases

\begin{tabular}{lc}
\hline primary tumour & estimate \\
\hline colorectal carcinoma $^{\mathrm{a}}$ & 127.4 \\
lung carcinoma $^{\mathrm{b}}$ & 13.0 \\
renal cell carcinoma $^{\mathrm{b}}$ & 30.3 \\
breast carcinoma $^{\mathrm{a}}$ & 56.3 \\
Other $^{\mathrm{a}}$ & 90.8 \\
\hline
\end{tabular}

${ }^{\mathrm{a}}$ mean ${ }^{\mathrm{b}}$ median

\section{DISCUSSION}

The presence of metastases in the adrenal glands is usually associated with a poor prognosis, as it demonstrates a disseminated metastatic process. However, in cases of isolated adrenal metastases survival can be improved after adrenalectomy [3, 11-13]. In our 19 patients with isolated adrenal metastases, the mean estimate survival was 25.0 months, which according to the results of other authors $[6$, 15-17]. Xin Ma et al. [18] have reported median estimate

survival of 24 months, and 5-year survival of $6.1 \%$ in a group of 75 patients with adrenal metastases. Carlos Zerrweck et al. [19] are established median survival of 48 months and 5-year survival of $45 \%$ in a group of 65 patients, which is much more than the above-mentioned reports. In their analysis, the longest median survival (84 months) was found in carcinoma of the kidney, followed by colorectal carcinoma ( 29 months), and the shortest survival was for lung carcinoma (12 months). The authors demonstrated a longer median survival in patients with metastases under $5 \mathrm{~cm}$ size (21 patients) compared with metastases over $5 \mathrm{~cm}$ (73 vs. 20 months, $\mathrm{p}=0.011)$. Strong et al. [15] also have reported better survival for metastases under $4.5 \mathrm{~cm}$, with a median survival in this group was 26 months, compared to 16 months in the group with metastases over $4.5 \mathrm{~cm}$. In our patients we found no statistical difference between tumour size and overall survival (log-rank test; $\mathrm{p}=0.621$ ), i.e. it was not to be a prognostic factor, as other authors have established in their studies and analyses [6, 14, 16, 17].

We have found that the type of tumour could serve as a prognostic factor for overall survival, with lung carcinoma demonstrating shorter survival compared to renal and 
other types of cancer (log-rank test; $\mathrm{p}=0.028)$. The diseasefree interval (DFI) was shorter for lung carcinoma, with median estimate survival of 13 months, followed by renal cell carcinoma- 30 months. The longest DFI was observed for colorectal carcinoma - 127 months. According to Lo et al. [3], patients with metastases from an adenocarcinoma had a better chance of survival. Muth et al. [17] have reported that patients with colorectal carcinoma have better outcomes than those with NSCLC. According to Paunovic et al. [8] the type of primary tumour does not influence survival. The survival difference between the different tumour types can be interpreted according to their biological behaviour.

According to certain authors $[3,17,18]$, there was no significant survival between patients with synchronous and patients with metachronous metastases. According to other reports $[6,14,15,20]$, patients with metachronous metastases had better survival than those with synchronous. Similar to the latter, in our analysis, we estimated the same: patients with synchronous metastases have significantly shorter survival those patients with metachronous metastases, with median survival 24.2 vs. 54.7 (log-rank test; $\mathrm{p}<0.0001)$. No patients with synchronous metastases who survived the end of the follow-up period, while $50 \%$ of those with metachronous metastases were still alive. Therefore, synchronous metastases were associated with short survival, but not an independent prognostic factor in multivariate analysis. On the contrary, according to Eu Chang Hwang et al. [21], synchronous metastases were an independent prognostic factor for overall survival, reported as $59.4 \%(n=19)$ for synchronous cases with DFI of 8.8 months. Howell et al. [22] reported that patients with synchronous metastases had significantly shorter survival than metachronous, with a median survival of 14 vs. 41 months, and 5 -year survival of $21 \%$ vs. $34 \%$, respectively $(\mathrm{p}=0.028)$. He described in $19 \%(n=11)$ synchronous metastases with
DFI $>12$ months in $39(81 \%)$ and median overall survival - 30 months. Muth et al. [17] demonstrated that the metachronous group with DFI $>12$ months was associated with 21-months longer median survival (log rank test, $\mathrm{p}=0.03$ ). In a multivariate analysis, Paunovic et al. [8] demonstrated that DFI $>12$ months was a statistically significant factor for better survival in patients with adrenalectomy due to metastases. In correspondence with the analyses of the above-mentioned authors, we also estimated that DFI $>12$ months is a prognostic factor for better survival (log-rank test; $\mathrm{p}=0.005)-27$ months longer median survival, compared to the group with DFI $<12$ months.

The first laparoscopic adrenalectomy (LA) for metastasis was carried out before 1999 by Heniford [11]. According to some authors $[11,12,14,16]$, it is a safe intervention and the oncological outcome is similar to that of open adrenalectomy (OA). Strong et al. [15] compared 31 LAs with 63 OAs. They described comparable rates of positive resection lines (22\% vs $29 \%)$, local recurrence $(11 \%$ vs $21 \%$ ) and overall survival (median 31 months vs 30 months). Muth et al. [17] did not find any statistical correlation between survival and surgical technique. Our analysis showed a significant difference in survival between the retroperitoneal approach and conversion to open adrenalectomy (median survival 59.2 vs 28.9 months).

\section{CONCLUSION}

The minimally invasive approach has proven benefits in patients with isolated adrenal metastases, making it a reasonable first-choice in those cases. On the other hand, our analysis in correspondence with other similar studies allowed us to conclude that lung carcinoma, short DFI < 12 months, presence of synchronous tumours and male gender determine shorter survival after adrenalectomy due to metastasis, and this warrants us to predict the future outcome of the intervention.

\section{REFERENCES:}

1. Abrams HL, Spiro R, Goldstein N. Metastases in carcinoma: analysis of 1000 autopsied cases. Cancer.1950; 3(1):74-85. [PubMed]

2. Bullock WK, Hirst AE Jr. Metastatic carcinoma of the adrenal. Am J Med Sci. 1953 Nov;226(5):521-4. [PubMed]

3. Lo CY, van Heerden JA, Soreide JA, Grant CS, Thompson GB, Lloyd RV, et al. Adrenalectomy for metastatic disease to the adrenal glands. $\mathrm{Br} J$ Surg. 1996 Apr;83(4):528-31. [PubMed]

4. Lam KY, Lo CY. Metastatic tumors of the adrenal glands: a 30-year experience in a teaching hospital. Clin Endocrinol (Oxf). 2002 Jan;56(1):95101. [PubMed]

5. Lenert JT, Bamett CC Jr, Kudelka
AP, Sellin RV, Gadel RF, Prieto VG, et al. Evaluation and surgical resection of adrenal masses in patient with a history of extra-adrenal malignancy. Surgery. 2001 Dec;130(6):1060-7. [PubMed] [CrossRef]

6. Kim SH, Brennan MF, Russo P, But ME, Coit DG. The role of surgery in the treatment of clinically isolated adrenal metastasis. Cancer. 1998 Jan; 82(2):389-94. [PubMed]

7. Glenn JA, Kieman CM, Yen TWF, Solorzano CC, Carr AA, Evans DB, et al. Management of suspected adrenal metastases at 2 academic medical canters. Am J Surg. 2016 Apr;211(4):66470. [PubMed] [CrossRef]

8. Paunovic I, Zivaljevic V, Diklic A, Tausanovic K, Stojanic R, Sipetic S.
Prognostic parameters after surgery for adrenal metastases: a single institution experience. Acta Chir Belg. 2014 MayJun;114(3):198-202. [PubMed]

9. Lee JE, Evans DB, Hickey RC, Sheman SI, Gagel RF, Abbruzzese MC, et al. Unknown primary cancer presenting as an adrenal mass: frequency and implications for diagnostic evaluation of adrenal incidentalomas. Surgery. 1998 Dec;124(6):1115-22. [PubMed]

10. Fong Y, Cohen AM, Fortner JG, Enker WE, Tumbull AD, Coit DG, et al. Liver resection for colorectal metastases. J Clin Oncol. 1997 Mar;15:93846. [PubMed] [CrossRef]

11. Heniford BT, Arca MJ, Walsh RM, Gill IS. Laparoscopic adrenalectomy for cancer. Semin Surg Oncol. 
1999 Jun;16(4):293-306. [PubMed]

12. Kebebew E, Siperstein AE, Clark OH, Duh QY. Result of laparoscopic adrenalectomy for suspected and unsuspected malignant adrenal neoplasms. Arch Surg. 2002 Aug;137(8): 948-953. [PubMed]

13. Zheng Q-Y, Zhang G-H, Zhang Y, Guo Y-L. Adrenalectomy may increase survival of patients with adrenal metastases. Oncol Lett. 2012 Apr;3(4): 917-920.

14. Sarela AI, Murphy I, Coit DG, Conlon KC. Metastasis to the adrenal gland: the emerging role of laparoscopic surgery. Ann Surg Oncol. 2003 Dec;10(10):1191-6. [PubMed]

15. Strong VE, D'Angelica M, Tang L, Prete F, Gonen M, Coit D, et al. Laparoscopic adrenalectomy for isolated adrenal metastasis. Ann Surg Oncol 2007 Dec;14(12):3392-400. [PubMed] [CrossRef]

16. Sebag F, Calzolari F, Harding J,
Sierra M, Palazzo FF, Henry JF. Isolated adrenal metastasis: the role of laparoscopic surgery. World J Surg 2006 May;30(5):888-92. [PubMed]

17. Muth A, Persson F, Jansson S, Johanson V, Ahlman H, Wangberg B. Prognostic factors for survival after surgery for adrenal metastasis. Eur J Surg Oncol. 2010 Jul;36(7):699-704. [PubMed] [CrossRef]

18. Ma X, Li H, Zhang X, Huang Q, Wang B, Shi T, et al. Modified anatomical retroperitoneoscopic adrenalectomy for adrenal metastatic tumor: technique and survival analysis. Surg Endosc. 2013 Mar 27(3):992-9. [PubMed] [CrossRef]

19. Zerrweck C, Caiazzo R, Clerquin B, Donatini G, Lamblin A, El Khatib Z, et al. Renal origin and size are independent predictors of survival after surgery for adrenal metastasis. Ann Surg Oncol. 2012 Oct;19(11):3621-6.

\section{[PubMed] [CrossRef]}

20. Mercier O, Fadel E, de Perrot M, Mussot S, Stella F, Chapelier A, et al. Surgical treatment of solitary adrenal metastasis from non-small cell lung cancer. J Thorac Cardiovasc Surg. 2005 Jul;130(1):136-40. [PubMed] [CrossRef]

21. Hwang EC, Hwang I, Jung S, Kang TW, Kwon DD, Heo SH, et al. Prognostic factors for recurrence-free and overall survival after adrenalectomy for metastatic carcinoma: a retrospective cohort pilot study. BMC Urol. 2014 May 23;14:41. [PubMed] [CrossRef]

22. Howell GM, Carty SE, Armstrong MJ, Stang MT, McCoy KL, Bartlett DL, et al. Outcome and prognostic factors after adrenalectomy for patients with distant adrenal metastasis. Ann Surg Oncol. 2013 Oct;20(11): 3491-6. [PubMed] [CrossRef]

Please cite this article as: Shumarova S, Petrov D, Grozdev K, Semkov A, Petrov D, Todorov G. Adrenalectomy for isolated metastases. J of IMAB. 2017 Jul-Sep;23(3):1651-1656. DOI: https://doi.org/10.5272/jimab.2017233.1651

Received: 27/05/2017; Published online: 18/08/2017

\section{Corresponding author:}

Svetlana Shumarova,

Department of Surgery, University Hospital “Aleksandrovska” Sofia, Medical University Sofia,

1, St. Georgi Sofijski Blvd, 1431 Sofia, Bulgaria,

E-mail: svetla_arn@abv.bg, 